\title{
Front Matter: Volume 7144
}

, "Front Matter: Volume 7144," Proc. SPIE 7144, Geoinformatics 2008 and Joint Conference on GIS and Built Environment: The Built Environment and Its Dynamics, 714401 (5 November 2008); doi: 10.1117/12.819193

Event: Geoinformatics 2008 and Joint Conference on GIS and Built Environment: Geo-Simulation and Virtual GIS Environments, 2008, Guangzhou, China 


\section{PROCEEDINGS OF SPIE}

\section{Geoinformatics 2008 and Joint Conference on GIS and Built Environment}

\section{The Built Environment and Its Dynamics}

Lin Liv

Xia Li

Kai Liu

Xinchang Zhang

Xinhao Wang

Editors

\section{8-29 June 2008 \\ Guangzhou, China}

Organized by

Sun Yat-sen University (China) • University of Cincinnati (USA) • CPGIS-The International Association of Chinese Professionals in Geographic Information Sciences

Co-organized by

Guangzhou Institute of Geography (China) - South China Normal University (China) • Guangdong Institute of Eco-Environmental and Soil Sciences (China) • Guangdong Association of Remote Sensing and Geographic Information Systems (China)

Sponsored by

NSFC—National Natural Science Foundation of China

Published by

SPIE

Volume 7144

Proceedings of SPIE, 0277-786X, v. 7144 
The papers included in this volume were part of the technical conference cited on the cover and title page. Papers were selected and subject to review by the editors and conference program committee. Some conference presentations may not be available for publication. The papers published in these proceedings reflect the work and thoughts of the authors and are published herein as submitted. The publisher is not responsible for the validity of the information or for any outcomes resulting from reliance thereon.

Please use the following format to cite material from this book:

Author(s), "Title of Paper," in Geoinformatics 2008 and Joint Conference on GIS and Built Environment: The Built Environment and Its Dynamics, edited by Lin Liu, Xia Li, Kai Liu, Xinchang Zhang, Xinhao Wang, Proceedings of SPIE Vol. 7144 (SPIE, Bellingham, WA, 2008) Article CID Number.

ISSN 0277-786X

ISBN 9780819473868

Published by

SPIE

P.O. Box 10, Bellingham, Washington 98227-0010 USA

Telephone +1 3606763290 (Pacific Time) · Fax +1 3606471445

SPIE.org

Copyright (c) 2008, Society of Photo-Optical Instrumentation Engineers

Copying of material in this book for internal or personal use, or for the internal or personal use of specific clients, beyond the fair use provisions granted by the U.S. Copyright Law is authorized by SPIE subject to payment of copying fees. The Transactional Reporting Service base fee for this volume is $\$ 18.00$ per article (or portion thereof), which should be paid directly to the Copyright Clearance Center (CCC), 222 Rosewood Drive, Danvers, MA 01923. Payment may also be made electronically through CCC Online at copyright.com. Other copying for republication, resale, advertising or promotion, or any form of systematic or multiple reproduction of any material in this book is prohibited except with permission in writing from the publisher. The CCC fee code is 0277-786X/08/\$18.00.

Printed in the United States of America.

Publication of record for individual papers is online in the SPIE Digital Library.

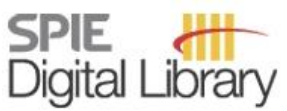

SPIEDigitalLibrary.org

Paper Numbering: Proceedings of SPIE follow an e-First publication model, with papers published first online and then in print and on CD-ROM. Papers are published as they are submitted and meet publication criteria. A unique, consistent, permanent citation identifier (CID) number is assigned to each article at the time of the first publication. Utilization of CIDs allows articles to be fully citable as soon they are published online, and connects the same identifier to all online, print, and electronic versions of the publication. SPIE uses a six-digit CID article numbering system in which:

- The first four digits correspond to the SPIE volume number.

- The last two digits indicate publication order within the volume using a Base 36 numbering system employing both numerals and letters. These two-number sets start with 00, 01, 02, 03, 04, 05, $06,07,08,09,0 \mathrm{~A}, 0 \mathrm{~B} \ldots \mathrm{OZ}$, followed by $10-1 \mathrm{Z}, 20-2 \mathrm{Z}$, etc.

The CID number appears on each page of the manuscript. The complete citation is used on the first page, and an abbreviated version on subsequent pages. Numbers in the index correspond to the last two digits of the six-digit CID number. 


\title{
Contents
}

\section{Part One}

\author{
XV Symposium Committees \\ xix Introduction
}

\section{LAND USE AND LAND COVER CHANGE}

714402 The conjugated evolvement of land use change with landscape pattern based on RS/GIS in watershed scale: a case study of middle and lower reaches of the Hanjing Basin [7144-01]

G. Yu, S. Yang, L. Hu, Z. Tu, X. Sun, Q. Luo, Central China Normal Univ. (China)

714403 Using anomaly detection method and multi-temporal Radarsat images for short-term land use/land cover change detection [7144-02]

J. Qian, Sun Yat-sen Univ. (China) and Guangzhou Institute of Geography (China):

X. Chen, The Univ. of Hong Kong (Hong Kong, China); X. Li, Sun Yat-sen Univ. (China);

A. G.-O. Yeh, The Univ. of Hong Kong (Hong Kong, China); B. Ai, Sun Yat-sen Univ. (China)

714404 The study on LUCC and its human drive factors in Quanzhou City [7144-03]

J. Zhuang, K. Zhong, Guangzhou Institute of Geography (China); J. Zhang, Guangdong Institute of Eco-Environment and Soil Science (China); S. Chen, Fujian Normal Univ. (China)

714405 Land-use/land-cover change detection using change-vector analysis in posterior probability space [7144-04]

X. Chen, J. Chen, M. Shen, W. Yang, Beijing Normal Univ. (China)

714406 A study on human driving mechanism of land use/cover change in rural villages from microscale: a case study of Zhaigou Village and Zhuangshang Village [7144-05] J. Liu, B. Li, J. Chang, Henan Univ. (China)

714407 Land use/land cover change geo-informative Tupu of Nujiang River in Northwest Yunnan Province [7144-06]

J. Wang, Y. Yang, Y. Huang, L. Fu, Q. Rao, Yunnan Normal Univ. (China)

714408 Landscape patterns and the optimal utilization of alpine grassland based on RS and GIS approach: a case study in TianZhu alpine grassland, Gansu Province, China [7144-07] J. Zhao, W. Wei, C. Feng, Northwest Normal Univ. (China); X. Wang, Cold and Arid Regions Environmental and Engineering Research Institute (China); J. Zheng, Northwest Normal Univ. (China)

714409 Urban land use change detection through spatial statistical analysis using multi-temporal remote sensing data [7144-08]

F. Li, M. Li, J. Liang, Y. Liu, Z. Chen, D. Chen, Nanjing Univ. (China)

7144 OA Research on land use/cover change of Wuhan based on object oriented image interpretation method [7144-09]

H. Zhu, A. Lin, Wuhan Univ. (China) 
$7144 \mathrm{OB} \quad$ Yangzhou City land use dynamic monitoring using multi-temporal remote sensing techniques [7144-10]

J. Huang, Tsinghua Univ. (China); X. Zhu, Central South Univ. (China); F. Mao, W. Zhou,

Tsinghua Univ. (China); Z. Tang, Central South Univ. (China)

7144 OC Land use/cover change detection based on span of land use map [7144-11]

H. Zhang, N. Shu, Wuhan Univ. (China)

7144 OD Trends and driving mechanism of land-use change in metropolitan areas of Pearl River Delta [7144-12]

F. Chen, South China Sea Institute of Oceanology (China), Guangzhou Institute of Geography (China), and Graduate Univ. of Chinese Academy of Sciences (China); H. Zhang, J. Wang, Guangzhou Institute of Geography (China); Q. Wu, South China Sea Institute of Oceanology (China), Guangzhou Institute of Geography (China), and Graduate Univ. of Chinese Academy of Sciences (China)

7144 OE Distinguishing the impacts of land use and arid process on natural potential productivity of cultivated land in the north farming pastoral zone of China [7144-13]

C. He, Y. Zhao, X. Li, P. Shi, Y. Yang, Beijing Normal Univ. (China)

7144 OF The urban expansion trends in the city of Nanjing based on RS and GIS [7144-14]

J. Yang, Y. Pu, Nanjing Univ. (China)

7144 OG Land use change and its driving forces in Beijing during 1996-2006 [7144-15]

Y. Chen, Institute of Geographical Sciences and Natural Resources Research (China) and Graduate Univ. of Chinese Academy of Sciences (China); J. Li, D. Zhu, China Agricultural Univ. (China)

$7144 \mathrm{OH} \quad$ Using projection pursuit learning network architecture to detect land use changes [7144-16]

B. Wu, Fuzhou Univ. (China) and The Chinese Univ. of Hong Kong (Hong Kong, China);

B. Huang, The Chinese Univ. of Hong Kong (Hong Kong, China); Y. Yan, Univ. of Science and Technology of Suzhou (China)

$7144 \mathrm{Ol} \quad$ A study of land use/land cover information extraction classification technology based on DTC [7144-17]

P. Wang, Y. Zheng, F. Yang, W. Jia, Shandong Univ. of Science and Technology (China);

C. Xiong, North China Univ. of Technology (China)

$71440 \mathrm{~J} \quad$ Visualizing research of land use land cover change [7144-18]

Y.-C. Wang, C.-C. Feng, National Univ. of Singapore (Singapore)

7144 OK Land use and environmental change analysis based on remote sensing: a case study of upper stream management of Hsin-Dian River [7144-19]

W.-C. Chen, C.-H. Liu, M.-H. Chen, T.-Y. Chou, Feng Chia Univ. (Taiwan)

$7144 \mathrm{OL}$ Development of spatio-temporal data model based on feature and time-varying sequence of events for land use in the mining area [7144-20]

J. Hu, Wuhan Univ. (China) and Xuzhou Normal Univ. (China); Z. He, Wuhan Univ. (China);

J. Kang, Xuzhou Normal Univ. (China); P. Liu, X. Wei, Wuhan Univ. (China) 
7144 OM Modeling urban growth with geographically weighted multinomial logistic regression [7144-21]

J. Luo, N. K. Kanala, Missouri State Univ. (United States)

7144 ON Land use/cover changes between 1990 and 2000 based on remote sensing and GIS in Pearl River Delta, China [7144-22]

Z. Chen, South China Institute of Environmental Science (China); X. Liu, Guangzhou Institute of Geography (China); X. Peng, Z. XU, South China Institute of Environmental Science (China); Z. Wu, Guangdong Institute of Ecological Environment and Soil Science (China)

$714400 \quad$ Location effect analysis of land using change in coal mining subsidence area based on RS and GIS [7144-23]

Q. Wu, Shandong Normal Univ. (China); N. Zhang, Shandong Jianzhu Univ. (China); Z. Liu,

J. Chang, T. Liu, Shandong Normal Univ. (China)

7144 OP Land resource change and its protective countermeasures in the Tumen River Region in China [7144-24]

F. Li, J. Xu, B. Zhang, Northeast Institute of Geography and Agricultural Ecology (China)

$71440 Q \quad$ Modeling the dynamics of urban growth using multinomial logistic regression: a case study of Jiayu County, Hubei Province, China [7144-25]

Y. Nong, Q. Du, K. Wang, Wuhan Univ. (China); L. Miao, South China Agricultural Univ. (China); W. Zhang, Wuhan Univ. (China)

7144 OR Land use change detection based on remote sensing classification and pixel comparison: a case study [7144-26]

X. Zhang, X. Tong, M. Liu, Tongji Univ. (China)

7144 OS Landscape change based on RS and GIS in the Jinghe basin, China [7144-27]

Y. Zhao, Y. Guo, C. Mao, Z. Ma, T. Li, Chang'an Univ. (China)

7144 OT Urban expansion analysis based on multi-temporal remote sensing and GIS in Wujiang, a typical desakota in Sunan, China (1978-2004) [7144-28]

Y. Zhu, X. Zhang, H. A, Hohai Univ. (China)

7144 OU Research of spatial structure of land-use change based on RS and GIS technology [7144-29]

X. Zhang, X. Xiong, Sun Yat-sen Univ. (China)

7144 OV Sensitivity of Landsat MSS and TM to land cover change in the Golden Horseshoe, Ontario, Canada [7144-30]

J. FitzGibbon, D. Chen, Queen's Univ. (Canada)

URBAN AND REGIONAL PLANNING AND DEVELOPMENT

7144 OW Assessments of Hangzhou urban growth near the Xixi wetland using remote sensing data [7144-31]

Q. Cheng, Zhejiang Gongshang Univ. (China) 
$71440 X \quad$ Strategic planning: building an enterprise geographical information system of Ras al Khaimah, United Arab Emirates [7144-32]

M. R. Bualhamam, United Arab Emirates Univ. (United Arab Emirates)

7144 OY The evaluation of land consolidation's benefits based on extensional matter-element model [7144-33]

H. Liu, Y. Liu, Y. Nong, L. Liu, Wuhan Univ. (China)

$7144 \mathrm{OZ}$ GIS-aided port area plane design on project for Dongluo island-port in Fuzhou [7144-34] W. Yang, Nanjing Univ. (China) and Nantong Vocational College (China); Y. Zong, J. He, Nanjing Univ. (China)

714410 GIS-based study on spatial growth of bi-polar with corridor in the Baltimore-Washington region in the USA [7144-35]

X. Zhang, Nanjing Univ. (China) and Hefei Univ. of Technology (China); Y. Zong, J. He, Nanjing Univ. (China)

714411 PM2006: a highly scalable urban planning management information system-Case study: Suzhou Urban Planning Bureau [7144-36]

C. Jing, Beijing Univ. of Civil Engineering and Architecture (China) and Zhejiang Univ. (China); S. Liang, China Univ. of Mining \& Technology (China); Y. Ruan, Beijing Consmation Ltd. Corp. (China); J. Huang, Zhejiang Univ. (China)

714412 Urban expansion analysis based on spatial variables derived from multi-temporal remote sensing imagery [7144-37]

Y. Yang, Wuhan Univ. (China) and China Univ. of Geosciences (China); Y. Wang, Hubei Provincial Meteorological Bureau (China); Q. Zhou, Hong Kong Baptist Univ. (Hong Kong, China); J. Gong, Wuhan Univ. (China)

714413 The spatial relationship analysis of regional development potential and resource and environment carrying capacity in China [7144-38]

Y. Zhang, J. Xu, G. Zeng, Q. Shen, Q. Hu, East China Normal Univ. (China)

714414 Remote sensing- and GIS-based analysis of construction land change in the late 1990s in the Sichuan Province [7144-39]

C. Yang, Univ. of Electronic Science and Technology of China (China) and Sichuan Normal Univ. (China); H. Huang, Sichuan Normal Univ. (China); S. Wang, Institute of Electronics (China); Z. Bai, Sichuan Normal Univ. (China); X. Cheng, Univ. of Electronic Science and Technology of China (China)

714415 Shanghai urban green landscape model system based on MapServer [7144-40] J. Rui, Shanghai Normal Univ. (China); B. Shi, Shanghai Institute of Tourism (China); D. Shen, W. Yao, Shanghai Normal Univ. (China)

714416 Study on data model of large-scale urban and rural integrated cadastre [7144-41] L. Peng, Wuhan Univ. (China); Q. Huang, Tsinghua Univ. (China); D. Gao, Wuhan Univ. (China) 
714417 The measurement for high-level and complex building and model in share property areas [7144-42]

H. Zhao, Wuhan Univ. (China) and Jiangxi Normal Univ. (China); Z. He, G. Cheng, Y. He, Wuhan Univ. (China); P. Li, Jiangxi Science \& Technology Teachers College (China)

714418 The coupling law of the interaction between economic development and ecoenvironment in medium-sized city: a case from Lianyungang city in China [7144-43] T. Li, Nanjing Normal Univ. (China) and Lianyungang Teachers College (China); Z. Lin, B. Xie, Nanjing Normal Univ. (China)

714419 Network-based spatial clustering technique for exploring features in regional industry [7144-44]

T.-Y. Chou, P.-H. Huang, L.-S. Yang, Feng Chia Univ. (Taiwan); W.-T. Lin, Ming Dao Univ. (Taiwan)

$71441 \mathrm{~A} \quad$ City positioning method based on streetlight [7144-45]

L. Guo, Y. Jiang, Y. Yang, N. Lou, Xi'an Univ. of Science and Technology (China)

7144 1B Dynamic change and quantitative analysis of Zhelin Bay based on multi-source spatial data [7144-46]

D. Zhang, Institute of Geographical Sciences and Natural Resources Research (China) and Graduate School of the Chinese Academy of Sciences (China); X. Yang, Institute of Geographical Sciences and Natural Resources Research (China); X. Sun, Institute of Geographical Sciences and Natural Resources Research (China) and Graduate School of the Chinese Academy of Sciences (China); J. Gong, Institute of Geographical Sciences and Natural Resources Research (China) and Wuhan Univ. (China); Y. Liu, Institute of Geographical Sciences and Natural Resources Research (China)

7144 1C Analysis of relationship between pedestrian facilities and urban morphology based on visibility [7144-47]

S. Ying, L. Li, Wuhan Univ. (China); Y. Gao, Wuhan Geotechnical Engineering and Surveying Institute (China); X. Zheng, Wuhan Univ. (China)

7144 1D Design and implementation of urban management GIS based on grid technology [7144-48]

Z. XU, Bureau of Urban Utilities and Landscaping of Guangzhou Municipality (China); X. WU, L. Yuan, South China Agricultural Univ. (China); L. Xie, Bureau of Urban Utilities and Landscaping of Guangzhou Municipality (China)

$71441 \mathrm{E} \quad$ Building extraction of urban area from high resolution remotely sensed panchromatic data of urban area [7144-49]

Y. Wang, Beijing Normal Univ. (China) and Peking Univ. (China); X. Li, Nanjing Univ. (China); W. Zhang, L. Zhang, Beijing Normal Univ. (China), Institute of Remote Sensing Applications (China), and Beijing Key Lab. for Remote Sensing of Environment and Digital Cities (China)

$7144 \mathrm{IF}$ The study on the real estate integrated cadastral information system based on shared plots [7144-50]

H. Xu, N. Liu, R. Liu, J. Huang, Zhejiang Univ. (China) 
7144 1G Research on public logistics centers of Zhenzhou city based on GIS [7144-51] Y. Zeng, S. Chen, Guangzhou Institute of Geography (China); Z. Tian, Zhengzhou Univ. (China); Q. Miao, Henan College of Engineering (China)

$7144 \mathrm{1H} \quad$ The research on the negative influence of real estate over-exploitation in urban waterfront to urban ecological environment and the countermeasures [7144-52]

Z. Jiang, Nanjing Univ. (China); N. Wang, Nanjing Univ. of Technology (China); T. Yu, B. Cui, K. Guan, Nanjing Univ. (China); X. Zhang, Weifang Institute of Surveying, Mapping and Geotechnical Investigation (China); R. Wang, Nanjing Univ. (China)

$714411 \quad$ Study on the spatial extension and distribution of industrial land in Tangshan based on RS and GIS [7144-53]

M. Men, Agricultural Univ. of Hebei (China); H. Pan, Institute of Mountain Hazards and Environment (China) and Graduate School of the Chinese Academy of Sciences (China); H. Xu, F. Liu, Agricultural Univ. of Hebei (China)

$71441 \mathrm{~J} \quad$ Valuing agricultural land standard prices based on agricultural land gradation and evaluation information system (ALGEIS) [7144-54]

Y. Liu, K. Wang, Y. Liu, N. Deng, Y. Liu, Wuhan Univ. (China)

$71441 \mathrm{~K}$ An urban-rural spatial development planning platform using GIS [7144-55]

F. Mao, W. Yu, W. Zhou, G. He, Tsinghua Univ. (China)

$71441 \mathrm{~L} \quad$ GIS-based approaches for planning support [7144-56]

Q. Zhan, Q. Pang, M. Deng, S. Zhou, Wuhan Univ. (China)

$71441 \mathrm{M}$ A study on spatial structure of urban system in the Northern China Plain based on radar remote sensing image [7144-57]

X. Wang, L. Wu, C. Mei, Z. Ruan, L. Liu, E. Bai, Anhui Normal Univ. (China) and Work Station of Anhui Province for Remote Sensing Archaeology (China)

$71441 \mathrm{~N} \quad$ A quantitative analysis of urban growth and associated thermal characteristics using Landsat satellite data [7144-58]

Y. Zeng, H. Zhang, B. Zou, H. Li, Central South Univ. (China)

714410 A study on the interaction and evolution of the spatial expansion and administrative division adjustment in Beijing metropolitan area [7144-59]

Y. Li, Shanghai Univ. (China); A. Dang, Tsinghua Univ. (China)

7144 IP Study on multi-scale urban planning supported by spatial information technology [7144-60] A. Dang, Tsinghua Univ. (China); X. He, Research Ctr. of Urban Development and Environment (China); Y. Li, Shanghai Univ. (China)

$71441 Q \quad$ Fragmentation of urban forms and the environmental consequences: results from a highspatial resolution model system [7144-61]

U. W. Tang, Z. S. Wang, Univ. of Macau (Macao, China)

7144 IR Design and compilation of the digital atlas of regional development in China [7144-62] Z. He, Wuhan Univ. (China); T. Cao, China Siwei Surveying and Mapping Technology Corp. (China); B. Jing, Wuhan Univ. (China) 
7144 is Measuring the suburbanization of Shanghai based on GIS [7144-63]

Z. Yin, Shanghai Normal Univ. (China); S. Xu, East China Normal Univ. (China)

7144 1T A new approach for subsurface space mapping of urban area using RS and GIS [7144-64] L. YU, D. Zhang, B. Xie, H. Zhang, Zhejiang Univ. (China)

\section{Part Two}

\section{GIS DEVELOPMENT AND MANAGEMENT}

$71441 U$ The research and realization of embedded GIS cross plafform technique [7144-65] Z. Hu, J. Li, Z. Wang, C. Yue, Zhengzhou Information Science and Technology Institute (China)

7144 IV Design and performance analysis of the police geographic information system with $B / S$ architecture [7144-66]

M. M. Zeng, C. Wang, J. Li, H. Sun, Huazhong Univ. of Science and Technology (China)

7144 IW Research and exploration on digital township [7144-67]

Y. Li, Y. Liang, Shandong Agricultural Univ. (China)

$71441 X \quad$ Research of E-government GIS [7144-68]

L. Li, China Univ. of Petroleum (China); H. Xia, Hangzhou Urban Planning Bureau (China);

J. Wan, China Univ. of Petroleum (China)

$71441 Y$ Standardization of CAD on measurement and recording of historic buildings [7144-69]

X. Ma, X. Zhou, Nanjing Univ. (China)

714412 Development of a forestry government agency enterprise GIS system: a disconnected editing approach [7144-70]

J. Zhu, B. L. Barber, Texas Forest Service (United States)

714420 Study on the spatial distribution of comfortable climate for tourism in Chongqing based on GIS [7144-71]

Z. Chen, Y. Gao, S. Yang, X. Yang, Chongqing Institute of Meteorological Science (China)

$714421 \quad$ Archaeology management system based on EV-Globe [7144-72]

L. Yang, G. Lu, A. Pei, Nanjing Normal Univ. (China); Y. Niu, Earth View Image Inc. (China);

T. Luo, Wuhan Second Ship Design and Research Institute (China)

714422 Digital forest implementation based on integration of GPS, GIS and RS [7144-73]

S. Liu, Institute of Remote Sensing Applications (China) and Graduate Univ. of Chinese Academy of Sciences (China); Y. Qiao, Institute of Remote Sensing Applications (China); Q. Wen, Institute of Remote Sensing Applications (China) and Graduate Univ. of Chinese Academy of Sciences (China)

714423 The evolution of geographic information systems from my view [7144-74]

D. Ye, Nanjing Univ. (China) and Nanjing Institute of City Transport Planning Co., Ltd. (China) 
714424 The design and implementation of 2D vector graphics interactive tools based on smart handle [7144-75]

X. Li, Information Engineering Univ. (China); S. Wang, Institute of Geographical Sciences and Natural Resources Research (China); Y. Hua, Information Engineering Univ. (China)

714425 Rural tourism spatial distribution based on multi-criteria decision analysis and GIS [7144-76] H. Zhang, Guangdong Polytechnic Normal Univ. (China); Q. Yang, Guangdong Univ. of Business Studies (China)

714426 Study on GIS-based sport-games information system [7144-77] H. Peng, China Sport Information Ctr. (China) and Northeast Normal Univ. (China); L. Yang, Northeast Normal Univ. (China); M. Deng, Hengyang Normal Univ. (China); Y. Han, Hunan Univ. of Science and Technology (China)

714427 Design and realization of intelligent tourism service system based on voice interaction [7144-78]

L. Hu, Y. Long, C. Qian, L. Zhang, G. Lv, Nanjing Normal Univ. (China)

714428 Application of IPv6 in GIS [7144-79]

Z. Wang, L. Wang, Chinese Academy of Surveying and Mapping (China)

714429 Study on urban land grading by evolutionary approaches to multi-objective spatial decision making [7144-80]

Y. Liu, Y. Liu, Z. Lan, Key Lab. of Geographic Information Systems (China) and Wuhan Univ. (China)

7144 2A The further development of legal cadastral domain model of China based on ontology [7144-81]

W. Zhang, Q. Du, Z. Zhao, Y. Guo, G. Cheng, Wuhan Univ. (China)

7144 2B An interoperable spatial decision support system based on geospatial semantic web technologies [7144-82]

C. Zhang, Univ. of Connecticut (United States); T. Zhao, Univ. of Wisconsin, Milwaukee (United States); W. Li, Univ. of Connecticut (United States)

7144 2C Robust smooth fitting method for LIDAR data using weighted adaptive mapping LS-SVM [7144-83]

S. Zheng, J. Ye, China Three Gorges Univ. (China); W. Shi, The Hong Kong Polytechnic Univ. (Hong Kong, China); C. Yang, China Three Gorges Univ. (China)

7144 2D Design and realization of tourism spatial decision support system based on GIS [7144-84] Z. Ma, Shandong Univ. of Science and Technology (China) and Institute of Geographical Sciences and Natural Resources Research (China); Q. Qi, Institute of Geographical Sciences and Natural Resources Research (China); L. XU, Shandong Univ. Of Science and Technology (China) and Taishan Univ. (China)

7144 2E Quantitative study on spatial distribution of geospatial industry in China [7144-85] L. Liu, Institute of Geographical Sciences and Natural Resources Research (China) and Graduate School of China Academy of Sciences (China) 
7144 2F Data management based on geocoding index and adaptive visualization for airborne LiDAR [7144-86]

X. Zhi, Wuhan Univ. (China)

$71442 \mathrm{G}$ A web-based spatial decision support system for spatial planning and governance in Guangdong Province [7144-87]

Q. Wu, South China Sea Institute of Oceanology (China), Guangzhou Institute of Geography (China), and Graduate Univ. of Chinese Academy of Sciences (China);

$\mathrm{H}$. Zhang, Guangzhou Institute of Geography (China); F. Chen, South China Sea Institute of Oceanology (China), Guangzhou Institute of Geography (China), and Graduate Univ. of Chinese Academy of Sciences (China); J. Dou, Guangzhou Institute of Geography (China) and Graduate Univ. of Chinese Academy of Sciences (China)

$71442 \mathrm{H} \quad$ Design and implementation of LUPMIS based on the customized GIS-Document Workflow [7144-88]

M. Li, Y. Shao, Z. Chen, Nanjing Univ. (China)

TRANSPORTATION, NETWORK, AND LOCATION ANALYSIS

$714421 \quad$ Study on spatial structure of retailing based on GIS in the city of Wuhan [7144-89]

C. Liu, Y. Tian, Hubei Univ. (China)

$71442 \mathrm{~J}$ Hedonic valuation of the spatial competition for urban circumstance utilities: case Wuhan, China [7144-90]

B. Zheng, Y. Liu, L. Huang, Wuhan Univ. (China)

$71442 \mathrm{~K} \quad$ Modeling the spatial resource allocation based on justice principle [7144-91]

K. Zhou, J. Wu, Y. Xiong, Z. Xu, L. Shi, East China Normal Univ. (China)

$71442 \mathrm{~L} \quad$ Research on modeling the overpasses for mapping and navigation [7144-92]

M. Deng, L. Fei, Wuhan Univ. (China)

$71442 \mathrm{M} \quad$ Urban drain layout optimization using PBIL algorithm [7144-93]

S. Wan, Y. Hao, D. Qiu, Beijing Univ. of Civil Engineering and Architecture (China); X. Zhao, Beijing Normal Univ. (China)

$71442 \mathrm{~N}$ Intercity commute patterns in central Texas [7144-94]

F. B. Zhan, Texas State Univ., San Marcos (United States); X. Chen, Northern Illinois Univ. (United States)

714420 The analysis of water network of Beijing-Tianjin region based on the complex network theory [7144-95]

J. He, Y. Zong, W. Yang, Nanjing Univ. (China)

$71442 \mathrm{P} \quad$ Schematic transportation network maps for wayfinding in urban environments [7144-96] W. Dong, Beijing Normal Univ. (China) and Chinese Academy of Surveying and Mapping (China); J. Liu, Chinese Academy of Surveying and Mapping (China); Q. Guo, Wuhan Univ. (China) 
$71442 \mathrm{~A}$ A circuitous shortest path algorithm labeled by previous-arc vector group in navigation GIS [7144-97]

L. Yang, S. Zhou, B. Wan, China Univ. of Geosciences (China); X. Pan, Xinyang Normal Univ. (China)

$71442 \mathrm{R} \quad$ A user profile model for intelligent delivery of spatial information [7144-98] Y. Xia, X. Zhu, D. Li, Q. Zhan, Wuhan Univ. (China)

$714425 \quad$ A non-planar data model for road networks based on GIS-T [7144-99] K. Xiao, J. Chen, D. Xiao, South China Agricultural Univ. (China); S. Ye, Zhongshan Univ. (China)

$71442 \mathrm{~T} \quad$ Using molecular systematics and GIS-based modeling approaches for selection of potential sites to explore the desirable microbial products [7144-100]

S. Yokwai, B. Phadermrod, E. Pacharawongsakda, S. Ingsriswang, National Ctr. for Genetic Engineering and Biotechnology (Thailand)

$71442 \mathrm{U} \quad$ Urban traffic safety analysis and assessment system based on GIS: system design, key techniques and implementation strategy [7144-101]

P. Du, China Univ. of Mining and Technology (China) and Key Lab. for Special Highway Engineering (China); J. Pei, Chang'an Univ. (China) and Key Lab. for Special Highway Engineering (China); X. Chen, Z. Yan, China Univ. of Mining and Technology (China)

$71442 \mathrm{~V}$ Measuring transit accessibility based on disaggregate data in GIS: the case of Wuhan, China [7144-102]

Z. Huang, X. Liu, Wuhan Univ. (China); M. Peng, Wuhan Urban Planning and Land Administration Information Ctr. (China)

$71442 \mathrm{~W} \quad$ An integrated GIS-based data model for multimodal urban public transportation analysis and management [7144-103]

S. Chen, Guangzhou Institute of Geochemistry (China), Naval Academy Research Institute (France), and Graduate School of the Chinese Academy of Sciences (China);

J. Tan, Guangzhou Institute of Geochemistry (China) and Guangzhou Sample Information Technology Co., Ltd. (China); C. Ray, C. Claramunt, Naval Academy Research Institute (France); Q. Sun, Guangzhou Institute of Geochemistry (China) and Graduate School of the Chinese Academy of Sciences (China)

$71442 \mathrm{X}$ Selection of comparative cases in land appraisal based on cloud model and gray relevancy theory [7144-104]

L. Yang, Y. Liu, W. Liu, Wuhan Univ. (China); X. Song, X. Xu, Xinxiang Municipal Bureau of State Land and Resources (China)

$71442 Y \quad$ Pedestrian navigation data modeling for hybrid travel patterns [7144-105] J. Zheng, Xinjiang Univ. (China); J. Tao, Peking Univ. (China) and Transportation Bureau of Xinjiang (China); J. Ding, A. Abuliz, Xinjiang Univ. (China); H. Xiang, Peking Univ. (China)

$71442 Z$ Time-series network analysis of civil aviation in Japan (1985-2005) [7144-106]

R. Michishita, B. XU, I. Yamada, The Univ. of Utah (United States) 
714430 Urban transportation of Beijing in a fast expansion based on the resident satisfaction survey [7144-107]

X. Li, Institute of Geographical Sciences and Natural Resources Research (China) and Graduate School of the Chinese Academy of Sciences (China); W. Zhang, F. Jin, Institute of Geographical Sciences and Natural Resources Research (China); M. Hong, Institute of Geographical Sciences and Natural Resources Research (China) and Graduate School of the Chinese Academy of Sciences (China); C. Wang, Institute of Geographical Sciences and Natural Resources Research (China)

$714431 \quad$ Using level of detail for underway path finding solution [7144-108] L. Niu, G. Zhu, Wuhan Univ. (China)

714432 The carbon reduction research of teaching staff commuting aided by Google Earth: taking Guangzhou University as an example [7144-109]

H. Xie, Wuhan Univ. (China) and Guangzhou Univ. (China); X. Wang, Guangzhou Urban Planning Automation Ctr. (China); M. Zhao, H. Zhao, Z. Lin, Guangzhou Univ. (China)

714433 Application of linear reference system and dynamic segmentation in the GIS-T [7144-110] L. Huang, H. Zhang, L. Yang, Northeast Normal Univ. (China); M. Deng, Hengyang Normal Univ. (China); H. Peng, China Sport Information Ctr. (China)

714434 Extended fractal analysis method and its application for linear rivers [7144-111] L. Wang, Y. Long, S. Cui, Nanjing Normal Univ. (China)

714435 Two improved algorithms of high degree seeking strategy for complex networks [7144-112] Y. Zhang, Q. Zhang, Sun Yat-sen Univ. (China)

714436 Artificial immune algorithm for multi-depot vehicle scheduling problems [7144-1 13] Z. Wu, Wuhan Univ. (China) and Sun Yat-sen Univ. (China); D. Wang, Hong Kong Baptist Univ. (Hong Kong, China); L. Xia, Wuhan Univ. (China) and Sun Yat-sen Univ. (China); $X$. Chen, Wuhan Univ. (China)

714437 Green space system design in Luoyang using Huff model [7144-114] S. Wang, M. Li, Henan Univ. (China)

714438 Object-oriented data model of the municipal transportation [7144-115] Y. Pan, Nanjing Normal Univ. (China) and Jiangsu Univ. (China); Y. Sheng, G. Zhang, Nanjing Normal Univ. (China)

714439 Signals of opportunity assisted ubiquitous geolocation and navigation technology [7144-116]

H. Tian, The Hong Kong Polytechnic Univ. (Hong Kong, China) and Sun Yat-sen Univ. (China); E. Mok, The Hong Kong Polytechnic Univ. (Hong Kong, China); L. Xia, Sun Yat-sen Univ. (China) and Wuhan Univ. (China); Z. Wu, Wuhan Univ. (China)

$71443 \mathrm{~A}$ The method study of building grid standard land price based on Thiessen polygon interpolation method [7144-117]

X. Peng, Wuhan Univ. (China) and Guangzhou Real Estate Appraisal Administration (China); L. Li, Guangzhou Real Estate Appraisal Administration (China) 
7144 3B Evaluating spatial equity of health service in Minhang District, Shanghai [7144-118]

Y. Shi, H. Chen, Y. Chen, Tongji Univ. (China)

7144 3C Time-space and cognition-space transformations for transportation network analysis based on multidimensional scaling and self-organizing map [7144-119]

Z. Hong, F. Bian, Wuhan Univ. (China)

7144 3D Spatial-temporal data model and fractal analysis of transportation network in GIS environment [7144-120]

Y. Feng, X. Tong, Y. Li, Tongji Univ. (China)

$71443 \mathrm{E}$ The research on data organization technology in the highway geographic information system [7144-121]

Z. Tian, F. Wu, Zhengzhou Univ. (China); Y. Zeng, Guangzhou Institute of Geography (China)

7144 3F Progressive street networks [7144-122]

J. Tian, Q. S. Guo, Wuhan Univ. (China); T. Zhan, Hubei Univ. of Policy (China)

Author Index 


\title{
Symposium Committees
}

\author{
Honorary Chairs
}

Guanhua Xu, Academician, Chinese Academy of Sciences (China)

Deren Li, Academician, Chinese Academy of Sciences, Wuhan

University (China)

Conference Chairs

Xia Li, School of Geography and Planning, Sun Yat-sen University (China)

Lin Liu, Department of Geography, University of Cincinnati (United States)

Proceedings Editor-In-Chief

Lin Liu, Department of Geography, University of Cincinnati (United States)

Xia Li, School of Geography and Planning, Sun Yat-sen University (China)

International Steering Committee

M.F. Goodchild, University of California, Santa Barbara (USA)

Michael Batty, University College London (United Kingdom)

John R. Townshend, University of Maryland, College Park (USA)

Robert McMaster, University of Minnesota (USA)

Harvey Miller, University of Utah (USA)

Nina Lam, Louisiana State University (USA)

Mark Gahegan, Penn State University (USA)

Qingxi Tong, Institute of Remote Sensing Application, Chinese Academy of Sciences (China)

Xiaowen Li, Beijing Normal University (China) and Institute of Remote Sensing Application, Chinese Academy of Sciences (China)

Gar-on Yeh, University of Hong Kong (China)

Jiyuan Liu, Institute of Geographical Sciences and Natural Resources Research, Chinese Academy of Sciences (China)

Jun Chen, National Center for Geomatics (China)

Yimin Jin, National Remote Sensing Center (China)

Lizhong Yu, East China Normal University (China)

Peijun Shi, Beijing Normal University (China)

Ke Liao, Institute of Geographical Sciences and Natural Resources Research, Chinese Academy of Sciences (China) 
Jicheng Cheng, Beijing University (China)

Xingyuan Huang, Nanjing University (China)

Jigang Bao, Sun Yat-sen University (China)

Technical Committee

Fang Qiu, Chair, University of Texas, Dallas (USA)

Xiaoxiang Chen, Chair, Sun Yat-sen University (China)

Lin Liu, Chair, Department of Geography, University of Cincinnati (United States)

Bingkai Ye, Chair, Guangdong Association of Remote Sensing and Geographic Information Systems (China)

Shuming Bao, University of Michigan (USA)

Richard Beck, University of Cincinnati (USA)

Ling Bian, State University of New York at Buffalo (USA)

Ruru Deng, Sun Yat-sen University (China)

Yongjiu Dai, Beijing Normal University (China)

John Eck, University of Cincinnati (USA)

Robert Frohn, University of Cincinnati (USA)

Huili Gong, Capital Normal University (China)

Jianhua Gong, Institute of Remote Sensing Applications, Chinese Academy of Sciences (China)

Jianya Gong, Wuhan University (China)

Peng Gong, Institute of Remote Sensing Applications, Chinese Academy of Sciences (China), University of California, Berkeley (USA), and Nanjing University (China)

Mei-Po Kwan, Ohio State University (USA)

Yong Lao, California State University, Monterey Bay (USA)

Bin Li, Central Michigan University (USA)

Jing Li, Beijing Normal University (China)

Qi Li, Peking University (China)

Zhilin Li, Hong Kong Polytechnic University (China)

Shunlin Liang, University of Maryland, College Park (USA)

Hui Lin, Chinese University of Hong Kong (China)

Yaolin Liu, Wuhan University (China)

Guonian Lu, Nanjing Normal University (China)

Mingming Lu, University of Cincinnati (USA)

Liqiu Meng, Technical University of Munich (Germany)

Jiaguo Qi, University of Michigan (USA)

Qingwen Qi, Institute of Geographical Science and Resources

Research, Chinese Academy of Sciences (China)

Qiming Qing, Peking University (China)

Yun Shao, Institute of Remote Sensing Applications, Chinese Academy of Sciences (China)

Shih-Lung Shaw, University of Tennessee (USA)

Wenzhong Shi, Hong Kong Polytechnic University (China)

Daniel Dianzhi Sui, Texas A\&M University (USA) 
Xinming Tang, Chinese Academy of Surveying and Mapping (China) Vicent Tao, Microsoft Corporation (USA)

Susanna Tong, University of Cincinnati (USA)

James Uber, University of Cincinnati (USA)

Yingjie Wang, Institute of Geographical Science and Resources

Research, Chinese Academy of Sciences (China)

Jingfeng Wang, Institute of Geographical Science and Resources Research, Chinese Academy of Sciences (China)

Fahui Wang, Louisiana State University (USA)

Le Wang, State University of New York at Buffalo (USA)

Xinhao Wang, University of Cincinnati (USA)

Lixing Wu University of Mining \& Technology (China)

David Wong, George Mason University (USA)

Lun Wu, Beijing University (China)

Bing Xu, University of Utah (USA)

Qingnian Zhang, Sun Yat-sen University (China)

Xinchang Zhang, School of Geography and Planning, Sun Yat-sen University (China)

Chenghu Zhou, Institute of Geographical Science and Resources Research, Chinese Academy of Sciences (China)

Qiming Zhou, Hong Kong Baptist University (China)

A-Xing Zhu, University of Wisconsin, Madison (USA)

Local Organizing Committee

Xinchang Zhang, Chair, School of Geography and Planning, Sun Yat-sen University (China)

Linyuan Xia, Chair, Sun Yat-sen University (China)

Kai Liu, Guangzhou Institute of Geography, Guangdong Academy of Sciences (China)

Qingnian Zhang, Sun Yat-sen University (China)

Zhijian He, Sun Yat-sen University (China)

Guoming Du, Sun Yat-sen University (China)

Haiyan Tao, Sun Yat-sen University (China)

Linbing Ma, Sun Yat-sen University (China)

Holly Arnold, University of Cincinnati (USA) 
Downloaded From: https://www.spiedigitallibrary.org/conference-proceedings-of-spie on 26 Apr 2023

Terms of Use: https://www.spiedigitallibrary.org/terms-of-use 


\section{Introduction}

All papers included in this volume are selected from the 16th International Conference on Geolnformatics and the Joint Conference on GIS and Built Environment organized by Sun Yat-sen University and the University of Cincinnati and held 28-29 June 2008 in Guangzhou, China. The Geoinformatics conference series was initiated by the International Association of Chinese Professionals in Geographic Information Sciences (CPGIS) in 1992. The Joint Conference on GIS and Built Environment is a new conference series initiated by Sun Yat-sen University and the University of Cincinnati.

The central theme of the combined conference is GIS, Built Environment, and Geo-simulation. The main topics included geo-simulation and virtual GIS environments, the built environment and its dynamics, the monitoring and assessment of natural resources and environments, advanced spatial data models and analyses, and classification of remote sensing images.

This combined conference provided a unique forum for exchanging ideas and knowledge on geo-information sciences between GIS professionals worldwide. This year's Geolnformatics conference is the largest ever. Over 800 participants came from 15 countries and regions, including the United States, the United Kingdom, Canada, Germany, Australia, South Africa, Turkey, Singapore, Malaysia, Thailand, United Arab Emirates, Mainland China, Hong Kong, Macau, and Taiwan. The organizers received more than 900 abstracts, and nearly 600 full papers. The conference program consists of 212 oral presentations and over 300 posters.

All papers in this volume are selected through a rigorous peer-review process. We believe that you will find these papers useful.

Finally, we would like to thank all authors and reviewers for their contributions to this volume.

Lin Liu and Xia Li Conference Co-Chairs Editors-In-Chief 
Downloaded From: https://www.spiedigitallibrary.org/conference-proceedings-of-spie on 26 Apr 2023

Terms of Use: https://www.spiedigitallibrary.org/terms-of-use 